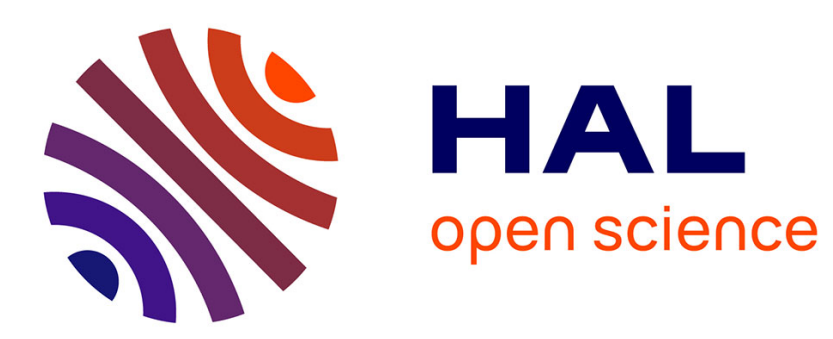

\title{
Progress in the understanding of the microstructure evolution of direct laser fabricated TiAl \\ Marc Thomas
}

\section{To cite this version:}

Marc Thomas. Progress in the understanding of the microstructure evolution of direct laser fabricated TiAl. THERMEC 2016, May 2016, GRAZ, Austria. hal-01354130

\author{
HAL Id: hal-01354130 \\ https://hal.science/hal-01354130
}

Submitted on 17 Aug 2016

HAL is a multi-disciplinary open access archive for the deposit and dissemination of scientific research documents, whether they are published or not. The documents may come from teaching and research institutions in France or abroad, or from public or private research centers.
L'archive ouverte pluridisciplinaire HAL, est destinée au dépôt et à la diffusion de documents scientifiques de niveau recherche, publiés ou non, émanant des établissements d'enseignement et de recherche français ou étrangers, des laboratoires publics ou privés. 
Progress in the understanding of the microstructure evolution of direct laser fabricated TiAl

M. Thomas (ONERA)

THERMEC 2016

GRAZ, AUTRICHE

29 mai-3 juin 2016

TP 2016-390

\section{$70^{2016}$ ans}




\title{
Progress in the understanding of the microstructure evolution of direct laser fabricated TiAl
}

\author{
THOMAS Marc* \\ ONERA, The French Aerospace Lab, Châtillon, F-92322 (France) \\ marc.thomas@onera.fr
}

Keywords: Selective Laser Melting - Direct Metal Deposition - gamma titanium aluminide heat treatments

\begin{abstract}
With the introduction of TiAl in aircraft jet engines, there is an increasing demand for the evaluation of novel processing routes for gamma titanium aluminides such as additive manufacturing (AM). A Ti-47Al-2Cr-2Nb powder material has been used as feedstock for laser fabrication of 3D samples by means of "Selective Laser Melting" (SLM) and "Direct Metal Deposition" (DMD). A number of processing parameters including laser power, laser scan rate, powder feed rate, have been varied to evaluate their effects on the material soundness. Optimised conditions can significantly reduce the crack sensitivity for this relatively low ductility material. In particular, crack-free experimental conditions have been identified by using additional heating strategies, thus limiting built-up residual stresses during fast cooling. The different samples have been examined using optical and scanning electron microscopy in the as-built condition. The non-equilibrium cooling conditions generate ultrafine and metastable structures exhibiting high microhardness values. A range of post-heat treatments have been performed to relieve the residual stresses and to tailor more uniform microstructures. Conventional heat treatments in the $\alpha+\gamma$ two-phase domain or in the $\alpha$ single phase domain have been successfully used to fully restore homogeneous microstructures either duplex or fully lamellar. A comparison is made with microstructures of both laser treated materials and of conventionally processed materials.
\end{abstract}

\section{Introduction}

Extensive work has been devoted to gamma titanium aluminides in the last two decades since property requirements for the low pressure turbine of the aircraft jet engines can be achieved. Thus, the cast $\mathrm{Ti}-(47-48) \mathrm{Al}-2 \mathrm{Cr}-2 \mathrm{Nb}$ alloy has been successfully implemented in the low pressure (LP) turbine of the GEnX jet engine (General Electric) [1]. However, investment casting introduces a columnar grain structure together with structural heterogeneities that are difficult to suppress by subsequent heat treatments. Therefore, the development of $\gamma$-TiAl alloys processed by powder metallurgy (PM) is considered promising with the uniform and texture-free microstructure obtained after compaction. In this context, additive manufacturing (AM) of $\gamma$-TiAl which starts from a powder batch has been investigated in particular for the potential microstructural uniformity that can be obtained.

A number of experimental works dedicated to AM of $\gamma$-TiAl alloys have been reported in the literature. For instance, a continuous deposition of Ti-47Al-2Cr-2Nb powder by Direct Metal Deposition (DMD) resulted in crack-free bulk samples [2]. However, subsequent heat treatments were needed to homogenize the microstructure. The cyclic heating and cooling during the deposition of the successive layers were found to be responsible for the inhomogeneous microstructure of as-built samples [3]. It has been established that, at each deposited layer, a metastable microstructure is formed which consists of a massive $\gamma$ phase on 
the top of the layer while the high temperature $\alpha$-phase was retained at the bottom of the layer, before being ordered to $\alpha_{2}-\mathrm{Ti}_{3} \mathrm{Al}$ during subsequent cooling [4]. This is consistent with the fact that a rapid rate of heat extraction occurs at the bottom of the layer, thereby leading to higher cooling rate. Another aspect which was reported by DMD processing is the directionally solidified columnar grain structure which is formed in the deposition direction due to the high temperature gradient [5]. However, subsequent heat treatment at $1125^{\circ} \mathrm{C}$ for 30 min was found inefficient to completely remove the compositional inhomogeneity of the as-deposited alloy [6]. Selective Laser Melting (SLM) of $\gamma$-TiAl alloys was also investigated, but with more difficulties to obtain crack-free samples [7-8]. Optimizing the process parameters by using intermediate scanning speeds $(150-300 \mathrm{~mm} / \mathrm{s})$ and laser powers $(100$ $250 \mathrm{~W})$ enabled to achieve stable beads. However, the as-built microstructure was inhomogeneous with coarser and finer regions next to each other due to the non-uniform cooling rate during the SLM process.

Based on this, the present work is aimed at investigating the influence of heat treatments for both SLM and DMD processes by using the commercial Ti-47Al-2Cr-2Nb (at.pct) alloy. These conventional post-heat treatments were given to the laser-built materials, first to relieve the residual stresses introduced by fast cooling, and second to homogenize the microstructure.

\section{Experimental procedure}

The nominal composition Ti-47Al-2Cr-2Nb (at. pct) alloy was used for this study since it is well known for its development in the eighties by General Electric [9]. The pre-alloyed powder was supplied by ATI Powder Metals (formerly Crucible Research), using gas atomization process. The atomized powder was sieved to collect powder particles smaller than $50 \mu \mathrm{m}$ for the SLM process and in the range 80-125 $\mu \mathrm{m}$ for the DMD process. Chemical analysis of the original powder was performed by plasma emission (ICP). As emphasized in Table 1, the alloy composition is close to the nominal composition with moderate gas impurities. The DMD campaign was carried out at ENSAM ParisTech by using a laboratory machine having a Trumpf Nd:YAG laser unit with a $\lambda=1.06 \mu \mathrm{m}$ wavelength and a laser power up to $4 \mathrm{KW}$. In parallel, the SLM campaign was performed at ENISE St Etienne (France) by means of a Phenix PM100 machine. A series of DMD and SLM experiments have been performed to identify the process parameters range for the achievement of fully dense and sound TiAl samples. The microstructure was examined by means of SEM observations of un-etched specimens which were performed in a Zeiss 962 DSM equipment. Complementary optical observations were made on some samples after etching with the Kroll reagent.

Table 1: Chemical Composition of the Initial TiAl Powder

\begin{tabular}{ccccccc}
\hline Ti (at. pct) & $\mathrm{Al}$ (at. pct) & $\mathrm{Cr}$ (at. pct) & $\mathrm{Nb}$ (at. pct) & $\mathrm{Fe}$ (at. pct) & $\mathrm{C} \mathrm{(ppm)}$ & $\mathrm{O}$ (ppm) \\
\hline 48.87 & 47.22 & 1.88 & 2.02 & 0.01 & 130 & 740
\end{tabular}

\section{Experimental results}

The build strategy for the SLM process consists in optimizing the speed of the laser beam for a good morphology of molten beads. Then, an adequate overlapping ratio of $25 \%$ was determined for the favorable scanning speeds by comparing different overlapping ratios from 0 to $30 \%$ between adjacent beads. Eventually, a number of $10 * 10 * 10 \mathrm{~mm}$ cubic samples have been produced with the best processing conditions. However, the pre-heated chamber at 
$200^{\circ} \mathrm{C}$ was not sufficient to relieve the residual stresses, thereby leading to some cracks. This is related to the multiple heating and cooling cycles with fast cooling rates. These residual stresses can be diminished at lower speeds, which logically generates less cracks by reducing the cooling rate. Because of the cumulative heating and cooling cycles, the microstructure was found to be rather inhomogeneous (Fig. 1a).

Compared to the SLM process, DMD results in much coarser microstructure in the as-built condition due to slower cooling (Fig. 1b). Actually, in the as-built condition, the areas solidified first exhibit a rather fine microstructure with almost equiaxed grains, whereas solidification propagates in the upper part with columnar dendrites perpendicular to the growth front. Moreover, the cracking sensitivity of this TiAl alloy was controlled by three main parameters, i.e. the scanning speed, the laser power and the powder feed rate. For instance, a lower scanning speed generates more power for the same amount of material, thus leading to a slower solidification. Moreover, by decreasing the powder feed rate at constant laser power, the melt pool temperature is increased which induces a slower solidification. Finally, a preheating stage achieved by using a defocused laser was found beneficial to promote a slower solidification and less residual stresses in the samples. Consistently, the SLM microstructure exhibits less cracks (Fig. 1c), and the DMD microstructure appears to be slightly more uniform than by using a focused laser (Fig. 1d).

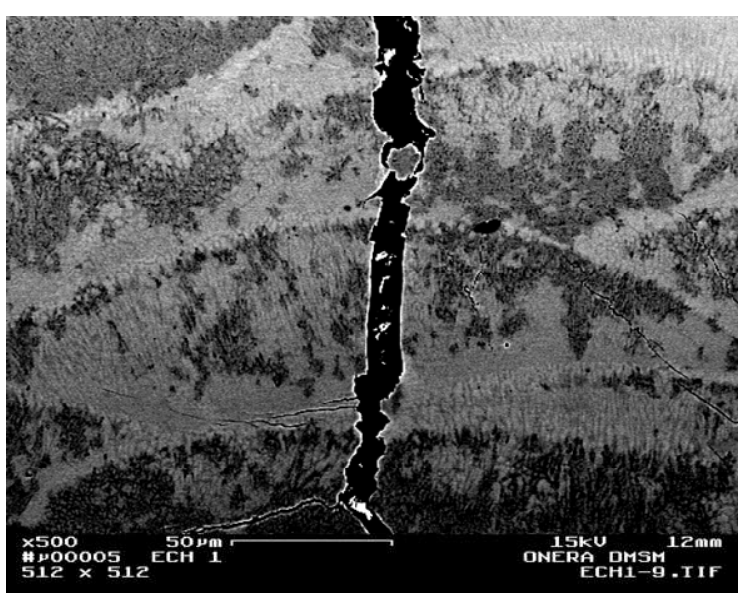

(a)

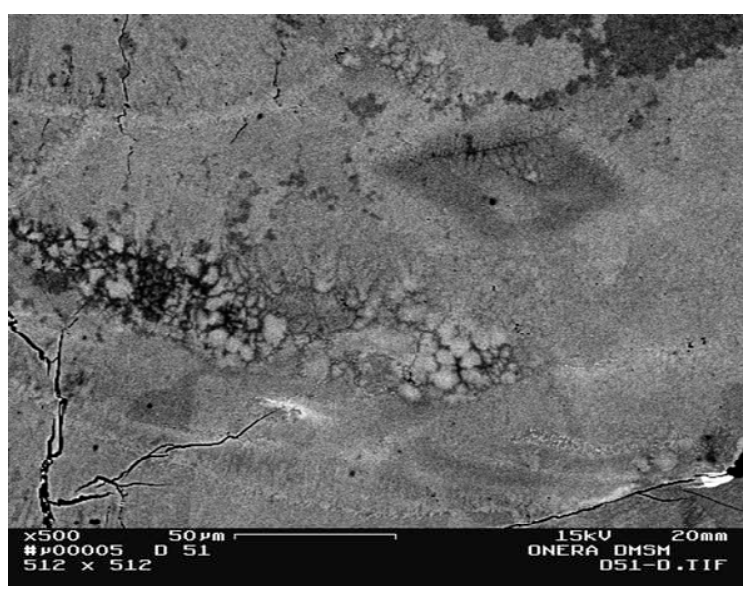

(c)

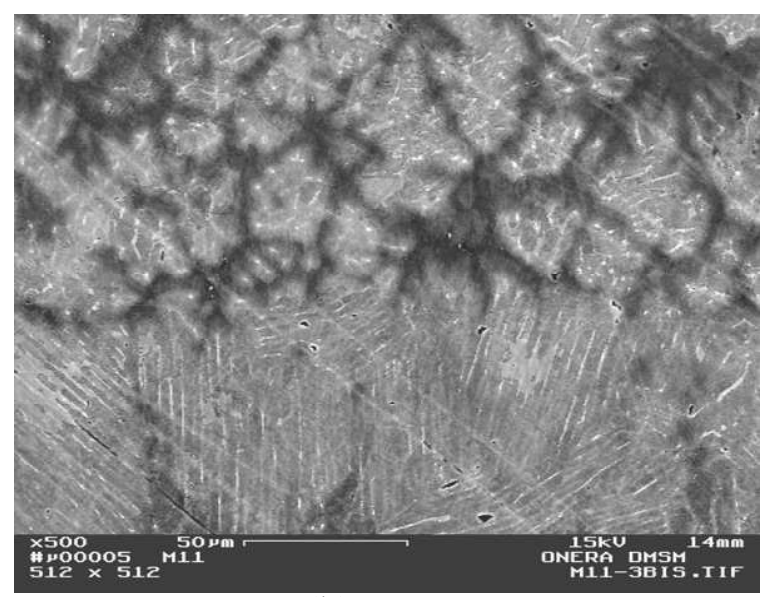

(b)



(d)

Fig. 1: SEM micrographs of samples in the as-built-condition, (a) SLM sample with focused laser, (b) DMD sample with focused laser, (c) SLM sample with defocused laser, (b) DMD sample with defocused laser 
Post-heat treatments were then applied for both SLM and DMD samples, in order to relieve the residual stresses and to homogenize the microstructure. As depicted in Figure 2 (blue dot), the first heat treatment consists of an isothermal treatment at a temperature below the orderdisorder transformation of the $\alpha$ phase, i.e. $1000^{\circ} \mathrm{C}$ for 24 hours in the two-phase $\alpha_{2}-\gamma$ domain, then followed by air cooling and by subsequent annealing at $900^{\circ} \mathrm{C}$ for 4 hours. Figures $3 \mathrm{a}$ and $\mathrm{b}$ show the related SLM and DMD microstructures which remain relatively similar to the as-built ones. It can be observed that the initial dendritic structure consists of $\gamma$ and $\alpha_{2}$ grains of approximately $5 \mu \mathrm{m}$ in size. Some micro-hardness measurements of the DMD sample reveal a significant decrease from $450 \pm 40 \mathrm{HV}(200 \mathrm{~g})$ in the as-built condition down to $280 \pm 10 \mathrm{HV}(200 \mathrm{~g})$ with this double heat treatment.

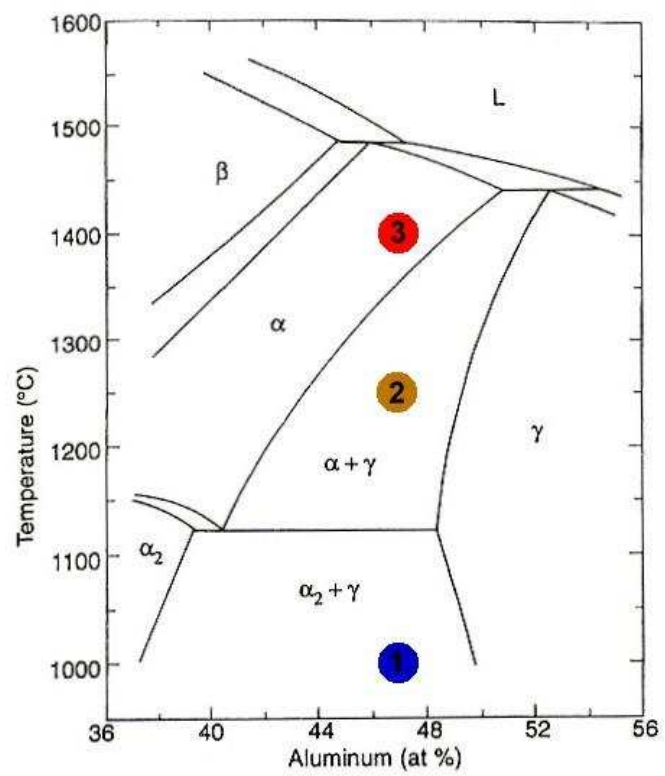

Fig. 2: Portion of the Ti-Al phase diagram with the related heat treatments.



(a)

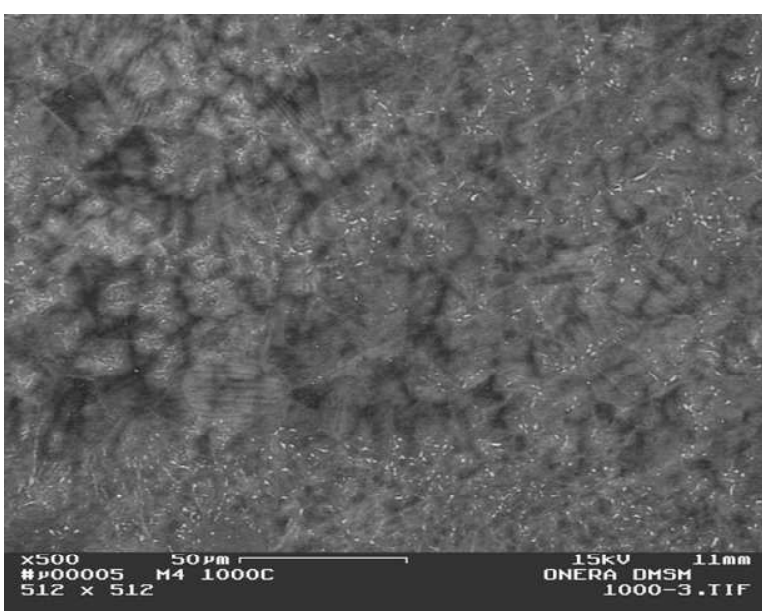

(b)

Fig. 3: SEM micrographs after heat treatment of 24 hours at $1000^{\circ} \mathrm{C}$ followed by 4 hours at $900^{\circ} \mathrm{C}$, (a) SLM sample, and (b) DMD sample. 
To achieve a more complete structural homogenization, the second heat treatment corresponds to an annealing in the two-phase $\alpha-\gamma$ domain as emphasized in Figure 2 (yellow dot). Isothermal annealing was carried out at $1250^{\circ} \mathrm{C}$ for 4 hours under argon followed by air cooling and a further ageing at $900^{\circ} \mathrm{C}$ for 4 hours under argon also followed by air cooling. A uniform duplex microstructure was then obtained with lamellar $\gamma+\alpha_{2}$ colonies as well as $\gamma$ grains. Moreover, some triple boundaries are decorated by a few Nb-rich precipitates (Figure 4).

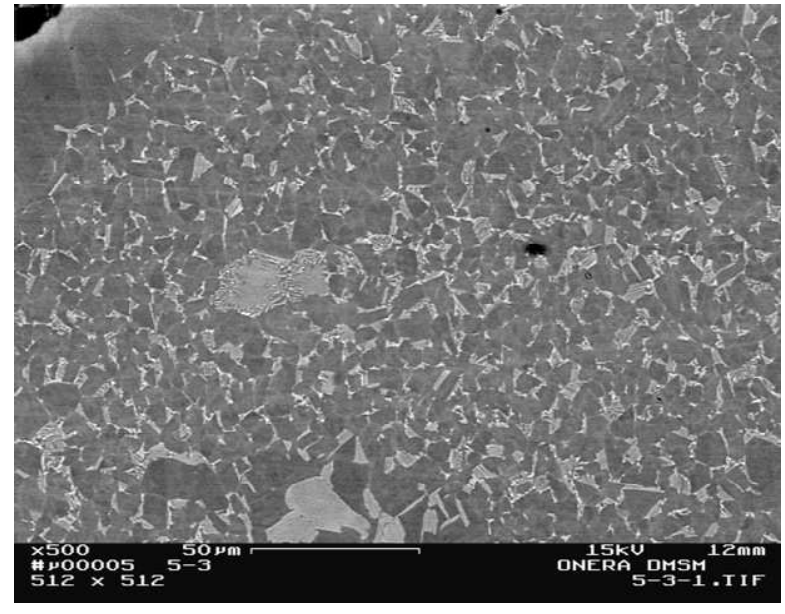

(a)

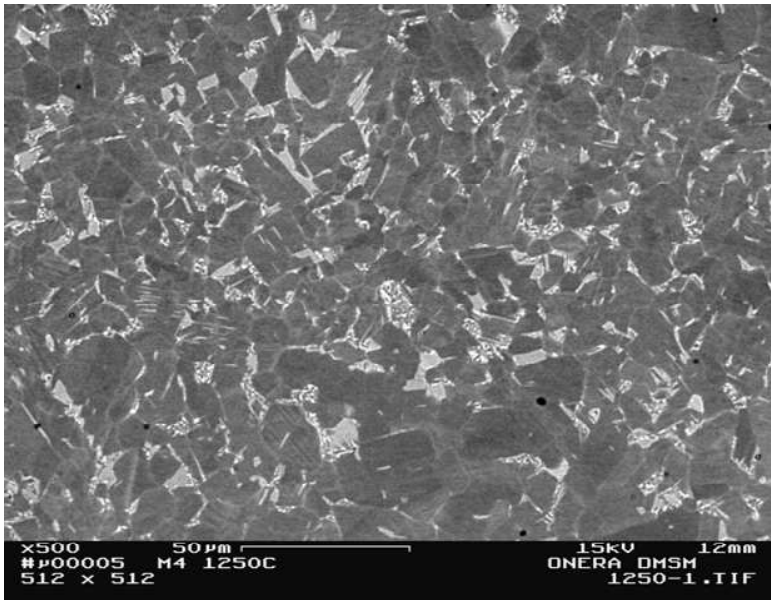

(b)

Fig. 4: SEM micrographs after heat treatment of 4 hours at $1250^{\circ} \mathrm{C}$ followed by 4 hours at $900^{\circ} \mathrm{C}$, (a) SLM sample, and (b) DMD sample.

A third heat treatment consists of an isothermal anneal of two hours at $1400^{\circ} \mathrm{C}$ in the $\alpha$ singlephase domain (red dot in Figure 2). The resulting microstructures for both SLM and DMD processes are characterized by a fully lamellar microstructure but with coarse lamellar colonies. It is expected that such a lamellar microstructure is not fine enough to promote adequate mechanical properties. For the homogenization purpose, the second heat treatment appears to be the more efficient, while preserving a refined microstructure.

\section{Conclusion}

A number of SLM and DMD process parameters have been varied in order to investigate the material soundness and the related microstructure of the commercial Ti-47Al-2Cr- $2 \mathrm{Nb}$ (at. pct) alloy. Due to the high cracking sensitivity of this TiAl material, the SLM process appears to be more difficult than the DMD process to produce crack-free samples. This results from the higher cooling rates that generate a higher level of residual stresses. The resulting asbuilt microstructures remain inhomogeneous with clear dendritic contrast and band structures. Post-heat treatments were therefore required to relieve built-up residual stresses during fast cooling and to promote a more homogeneous microstructure. A conventional heat treatment in the two-phase $\alpha-\gamma$ domain can be successfully used to restore a more uniform and duplex microstructure, which is known as a crucial point to guarantee a lower scatter for mechanical properties. 


\section{Acknowledgements}

The authors would like to acknowledge the FRAE (Fondation de Recherche en Aéronautique et Espace) institution for their financial support.

\section{References}

[1] S.F. Clark, 787 Propulsion System, Aero Quarterly, Available from:http://www. boeing.com/commercial/aeromagazine/articles/2012_q3/2/

[2] J.H. Moll, E. Whitney, C.F. Yolton and U. Habel, Laser Forming of Gamma Titanium Aluminide, Gamma Titanium Aluminides 1999, Y-W. Kim, D.M. Dimiduk, M.H. Loretto, H. Clemens and H.H. Rosenberger (eds.), The Minerals, Metals \& Materials Society, 1999, pp. 255-263

[3] D. Srivastava, D. Hu, I.T.H. Chang and M.H. Loretto, The influence of thermal processing route on the microstructure of some TiAl-based alloys, Intermetallics. 7 (1999) $1107-1112$

[4] X.D. Zhang, C. Brice, D.W. Mahaffey, H. Zhang, K. Schwendner, D.J. Evans and H.L. Fraser, Characterization of Laser-Deposited TiAl Alloys, Scripta materalia. 44 (2001) 24192424

[5] H.P. Qu and H.M. Wang, Microstructure and mechanical properties of laser melting deposited $\gamma$-TiAl intermetallic alloys, Materials Science and Engineering A. 466 (2007) 187194

[6] H.P. Qu, P. Li, S.Q. Zhang, A. Li and H.M. Wang: The effects of heat treatment on the microstructure and mechanical property of laser melting deposition $\gamma$-TiAl intermetallic alloys, Materials and Design. 31 (2010) 2201-2210

[7] L. Löber, R. Petters, U. Kühn and J. Eckert, Selective Laser Melting of Titaniumaluminides, 4th International Workshop on Titanium Aluminides, September 13th 16th, 2011, Nürnberg, Germany

[8] L. Löber, F. P. Schimansky, U. Kühn, F. Pyczak and J. Eckert, Selective laser melting of a beta-solidifying TNM-B1 titaniumaluminide alloy, Journal of Materials Processing Technology. 214 (2014) 1852-1860

[9] S.C. Huang, U.S. Patent 4,879,092. (1989) 